\title{
\#nomakeupselfies: the Face of Hashtag Slacktivism
}

\author{
CLAIRE HAMPTON Brunel University London
}

\begin{abstract}
This article interrogates the significance of the selfie in the construction of contemporary female identity through a close analysis of the \#nomakeupselfie meme. Drawing on the distinct but conversant theoretical frameworks of cyber-feminisms, post-feminisms and breast cancer culture, it involves both a theoretical investigation and a phenomenological reflection on the selfie trend in question. Mobilizing Foucault's concept of governmentality, which he used to contextualise the link between technologies of domination and his later postulations on technologies of the self, the article explores the oppositional feminist viewpoints regarding empowerment and agency in online identity construction. It also constitutes an auto-ethnographic response to the phenomenon from my nuanced position as a young, female, selfie-taking, feminist, academic, breast cancer survivor. The analysis of the \#nomakeupselfie meme focuses on three central issues: the problematic relationship between breast cancer and beauty; the trivialization, infantilisation and sexualisation of the disease inherent in contemporary breast cancer culture and the self-commodification of the female body as part of a consumer activist transaction.
\end{abstract}

\section{KEYWORDS}

\#nomakeupselfie, gender, breast cancer, post-feminisms, technologies of the self, governmentality, commodification, consumer activism, pink ribbon culture. 
In March 2014, the practice of selfie-taking escalated across Britain and North America as the \#nomakeupselfie became a viral spectacle that suffused social media environments for over a week. Participants in the No-Slap-Snap trend were nominated by friends through the social media practice of tagging and required to post 'self-taken photographs showing them with faces bare of cosmetics' (Ferreday 2014, 141). The activity, which spread virally thanks to the participation of celebrities with large social media followings, was perpetuated in the name of cancer research, specifically breast cancer. The practice, framed by the pink ribbon culture, which has come to symbolize the disease, was apparently a means of 'raising donations [...] or more vaguely, raising awareness' (Ferreday 2014, 141).

This article interrogates self-representation that occurs at the intersection between three distinct theoretical frameworks; cyber-feminisms, post feminisms and breast cancer awareness. Through an analysis of the \#nomakeupselfie meme it questions the significance of the selfie as part of the growing trend in 'hashtag activism'. Mobilizing Foucault's theory of 'governmentality', the link between technologies of domination and his later postulations on technologies of the self, this essay begins by offering a contextualizing review of the debate regarding empowerment and agency inherent in the practice of self- shooting. The article interweaves personal experience and reflection alongside a critical, theoretical investigation to problematize selfie-taking in relation to cancer awareness. The \#nomakeupselfie craze is an example of what social commentators refer to as 'hashtag activism' or more cynically 'slacktivism'; a growing trend to engage with charitable causes in a self-documenting virtual way that speaks to activism but in reality involves little effort. As a breast cancer survivor, I employ a phenomenological methodology to analyze the narcissism / altruism binary that can be identified in mediatized forms of activism.

The \#nomakeupselfie trend was as contentious as it was successful; despite raising the staggering amount of approximately $£ 8$ million for cancer research, the phenomenon very quickly came under close scrutiny and was subject to overt criticism from various cultural and theoretical camps. Condemnation of the \#nomakeupselfie ranged from anti-capitalist critiques that participants were complicit dupes in the multi million pound cancer industry, to the notion that the practice constituted 'a slap in the face to women with cancer' (Park 2014). Most typically the images, and perpetuators of them, were lambasted for being solipsistic and demonstrative of a contemporary narcissistic turn in visual culture. These critiques resonated with the wider condemnation of the 'selfie generation' (Ferreday 2014, 142), employing a totalizing view that read and dismissed the images as a promotion of patriarchal beauty standards and the subordination of women.

Deborah Ferreday argues that canonical feminism's categorization of the \#nomakeupselfie as evidence of women's subordination is dismissive. She suggests that this type of reading is not only 'more violent and sexist than any supposed hidden message encoded in a selfie' but that in reading these images as a sign of feminist failure we disregard 'a sophisticated and self-aware rejection of masculinist values' (Ferreday 2014, 143).

Whilst Ferreday's defense of no make-up selfies is cognate with a wider analysis of young women and femininity in popular culture, within the context of breast cancer diagnosis, treatment and survivorship the suggestion of 'self-awareness' is complexified. As a breast cancer survivor my reservations regarding the \#nomakeupselfie centred around three main issues: the problematic relationship between breast cancer and beauty; the trivialization, infantilisation and sexualisation (Sulik, 2014) of the disease inherent in contemporary breast cancer culture; the selfcommodification of the female body as part of a consumer activist transaction. This article offers a post-feminist reading of these critiques that interrogates Naomi Wolf's 'Beauty Myth' in the context of the feminine paradox inherent in breast cancer. 
Selfies are now contemporaneous with our rising preoccupation with cyber inter-activity and are regarded by many 'as proof of the vainglory of contemporary social media obsessions' (Losh 2014, 1) and a practice that dramatizes an individualistic turn in visual culture. Selfie-taking is steeped in ever changing culturally significant codes and rules that stretch well beyond its simple definition. Ideologies regarding poses, angles, back-ground, lighting or clothing are in constant flux and a socially acceptable configuration relies on a complex formula of subjective capital currency such as gender, age and social standing. Whilst selfies are by no means the sole domain of women, research such as the Selfiecity project has found that women are up to 4.6 times more likely to engage in the practice than men. The criticism levied at the no make-up selfie trend is typical of a wider 'antiselfie' discourse in contemporary left wing and feminist rhetoric that positions young post-feminist women as emblematic of the 'selfie generation' (Ferreday 2014, 142).

The fluctuating codes and taxonomies of selfie taking are the subject of much analytical debate. Attempts to deconstruct the multiple concurrent semiologies inherent in the practice of self-shooting have revealed a rift in contemporary feminist discourse. It is not my intention to over extrapolate on this wider debate in the parameters of this article as this would inevitably lead to a gross oversimplification that was inaccurately totalizing; feminist selfie scholarship spans a wide range of interdisciplinary theories, debates and practices that engage with gender and digital culture. It is, however, necessary to contextualize my phenomenological reading of the spontaneous selfdocumenting, mediatized performance of femininity inherent in no make-up selfies, through the framework of this wider (post) feminist debate. Whilst the field is complex and pluralistic, two distinct tropes of thought dominate the gendered selfie practice debate; empowerment and agency versus passive narcissism and patriarchal conformity.

\section{Empowerment and agency}

Champions of the selfie suggest that, rather than a symptom of self- obsession and vanity, selfies offer the potential for self-representation, empowerment and visibility; mobilizing the radical potential of the internet to disrupt the ordinary ways our identities are shaped. As Waskul et al suggest, the absence of corporeal bodies in cyberspace results in representation of the body through 'image, descriptive codes, words of expectations, appearance, and action' $(2000,378)$. This has given rise to a reversal of the notion that self is something that is embodied; 'in online communication environments both bodies and selves exist only as socially constructed representations' (Waskul et al 2000, 378). These symbolic bodies are shaped, governed and liberated by our disembodied online identities. This line of reasoning is founded in cyber-feminism and a utopian conceptualization of a mediatized world beyond the categories and hierarchies of gender, race and class, 'no longer structured by the polarity of public and private' (Haraway in Kirkup et al 2000, 1.3).

Cyber-feminism is not a monolithic movement but a distinct range of political stances and theories that are unified by a common focus on gender and digital technology (Daniels 2009, 103). Cyberfeminisms acknowledge that women are simultaneously exploited and complicit within hegemonic, networked techno-scientific discourse. The post-corporeal and decentralized space for communication offered by the internet heralded a democratized public arena or, as Faith Wilding suggests, a 'free space where gender does not matter - [where] you can be anything you want to be regardless of your "real" age, sex, race, or economic position ...' (Wilding 1998 in Pitts 2004, 35). Donna Haraway's A Manifesto for Cyborgs: Science, Technology and Socialist-Feminism in the Late Twentieth Century (1985) is traditionally acknowledged as a crucial element in the inception of cyber-feminisms. Haraway's conception of a cyborg as 'a cybernetic organism, a hybrid of machine and organism, a creature of social reality' (Haraway in Kirkup et al 2000, 1.3), is an authentic 
means of defining those of use who are 'tethered to technologies' (Markham 2013, 289). Digital, networked devices now play an active role in our interactions with others. Technologies structure our daily routines as more of our lives are played out in mediatized public arenas. We make decisions about, and maintain, the appearance of our online profiles and are active agents in the representation of specific aspects of ourselves to particular audiences. By embracing the fluidity of online identities we combat traditional and symbolic forms of oppression and constraint. When women self shoot to celebrate their appearance, preserve memories or locate themselves in a specific place at a specific time, the viewed is the overseer of her viewing and is thus empowered to repudiate and resist traditional patriarchal objectification. A sentiment echoed in Tiidenberg's 2014 article where selfies are described as 'empowering exhibitionism that allows us to reclaim a copyright to our lives'.

Rather than passive subjects, the pro-selfie contingent advocates selfie takers as active agents in the construction and surveillance of their own bodies. According to Foucault the process of selfconstitution is the means by which we become self-determining agents capable of challenging and resisting the structures of domination in society. Read in this ideological context the practice of selfying can be understood as a postfeminist 'acceptance of femininity and a refusal to internalize masculinist values' (Ferreday 2014, 147).

Foucault's theories of discipline are often cited in self-documentation discourse, particularly 'technologies of the self', the concept of self regulation and cultivation, 'whereby individuals effect by their own means a certain number of operations on their own bodies so as to transform themselves in order to attain a certain state of happiness, purity, wisdom, perfection or immortality' (Foucault 1988, 18). Foucault's writing on 'technologies of the self' explores the autonomous individuals capacity for self control, building on his earlier studies, which had focused primarily on modes of discipline identified as 'technologies of domination' (1977). His studies centred on the hermeneutics of the self as featured in Greco-Roman philosophy and Christian spirituality. He contextualised this interpretation by applying it to a set of practices from late antiquity the precept of which was 'to be concerned with oneself' (Foucault 1988). Despite this original historical context these postulations have proven to be an applicable and effective critical framework through which to consider contemporary culture.

The link between 'technologies of domination' and 'technologies of the self' is something that Foucault developed in two lectures delivered in 1978 and 1979 at the College de France. He termed the bridge between these two categories of power 'governmentality'. The social theorist Thomas Lemke explains 'governmentality' as:

...the points where technologies of domination of individuals over one another have recourse to processes by which the individual acts upon himself. And conversely, $[\ldots]$ the points where the techniques of the self are integrated into structures of coercion and domination. $(2002,52)$

Lemke suggests that the way individuals conduct themselves is governed by their interaction with others, we construct and modify our selves through self -governed processes in a negotiation with, rather than an internalisation of, structures of power and domination. Governmentality requires the analysis of the plurality of power forces that shape human action and interaction. I suggest that as a perspective 'that seeks to connect government, politics and administration to the space of bodies, lives, selves and persons' (Dean 2010,20) it is a powerful paradigm through which to consider the practice of selfies. Rather than a means of disciplining and controlling the way women present themselves, selfies offer a platform through which women enter into a dialogue with hegemonic 
ideology; a process whereby 'the self continuously has to be measured, judged and disciplined in order to gear personal "empowerment"'(Lemke 2002, 61).

\section{Passive narcissism and patriarchal conformity}

Haraway's cyborg is 'a creature in a postgender world' (Haraway in Kirkup et al 2000, 1.3), a being that is not a symbiotic unification of traditional gender binaries, but an entity that transcends essentialist polarized notions of identity altogether. This concept of a being that is unimpeded by identification and a refusal to accept femininity as a naturally unifying category is the locus of the cyborg's promise of subversion and liberation. The counter selfie argument questions this notion of cyber-liberation suggesting that despite the potential of the net as a forum for diversity, online identities tend to be constructed in rigid adherence to, and affirmation of, social norms. As selfying subjects we are at liberty to control the angle of the camera and snap as many shots as we require before refining, editing and filtering the one that we are willing to share; yet selfies often exhibit extreme body and gender conformity in a technologized reflection of the way patriarchal society continues to indoctrinate women to prioritize appearance.

This critique of selfie culture is rooted in the traditional feminist debate surrounding autocratic beauty ideology. Naomi Wolf, one of the most identifiable post-feminist writers of the 1990s, famously reiterated the feminist doctrine that women are coerced by society to fetishize and strive towards unrealistic aesthetic ideals of femininity. She termed this phenomenon 'The Beauty Myth', suggesting that as women began to transgress traditional, marginalized roles of the domestic sphere and take up positions of power across a range of previously male dominated domains such as politics, industry and economics the beauty ideology solidified as a litigation-free way to discriminate against women. She suggests that the dominant norms of feminine beauty were heavily propagated during the 1980 s as society began to 'defend itself by evading the fact of real women, our faces and voices and bodies, and reducing the meaning of women to these formulaic and endlessly reproduced "beautiful" images' (Wolf 1991, 18). The feminist academic Susan Bordo suggests that 'the discipline and normalization of the female body [...] has to be acknowledged as an amazingly durable and flexible strategy of social control' $(1995,166)$. Left wing feminist rhetoric draws on this discourse, regarding 'the contemporary preoccupation with appearance' (Bordo 1995, 166), to admonish the practice of young female selfie takers and categorize them as complicit victims of homogenizing, ideological beauty aesthetics.

The internet is permeated by consumerism, operating as a mass media delivery system, bombarding us with images that prescribe how our bodies should look. Via our membership to this cyber-society we are susceptible to bio-political capitalist sway, 'technologies of domination' (Foucault 1977). As a result of the homogenizing effects of cyber-consumer culture, dominant norms become internalised and perpetuated by means of a virtual panopticon; the monolithic cyber footprint that those of us who are social media users occupy. The threat of panoptic dystopia is well documented in contemporary media studies. Here similarly to Westlake (2008) I apply the perspective to Facebook. Bentham's panopticon, as documented by Foucault in Discipline and Punish, is a 'gaol design where each prisoner may always be watched by an invisible guard, hence prisoners assume constant surveillance, internalize the gaze and discipline themselves' (Schwarz 2011, 2). On Facebook each user occupies a profile identical in layout and format to the other 1.23 billion users, social media then operates as 'a type of location of bodies in space, of distribution of individuals in relation to one another, of hierarchical organisation' (Foucault 1977, 205). Foucault suggests 'visibility is a trap' claiming that the effects of the panopticon ' induce in the inmate a state of conscious and permanent visibility that ensures the automatic functioning of power' $(1977,200-$ 201). Social media subjects us to a field of visibility, through instantaneous interfacing we 
continuously view the activity of others via news feeds and updates and are ourselves under, potentially, constant anonymous surveillance yet as Westlake suggests, Facebook users do not continuously act as subjects of surveillance (Westlake 2008, 36). The virtual panopticon analogy falls short. Whilst as users of social media we 'inscribe in ourselves the power relation in which we simultaneously play both roles' (Foucault 1977, 203), these virtual forums are more than a networked site for policing and establishing normative ideologies. They collapse the duality of freedom and ideological power, acting as a 'contact point' for 'technologies of domination' and 'technologies of the self' embodying Foucault's notion of 'government'.

\section{Is the selfied body a 'docile body'?}

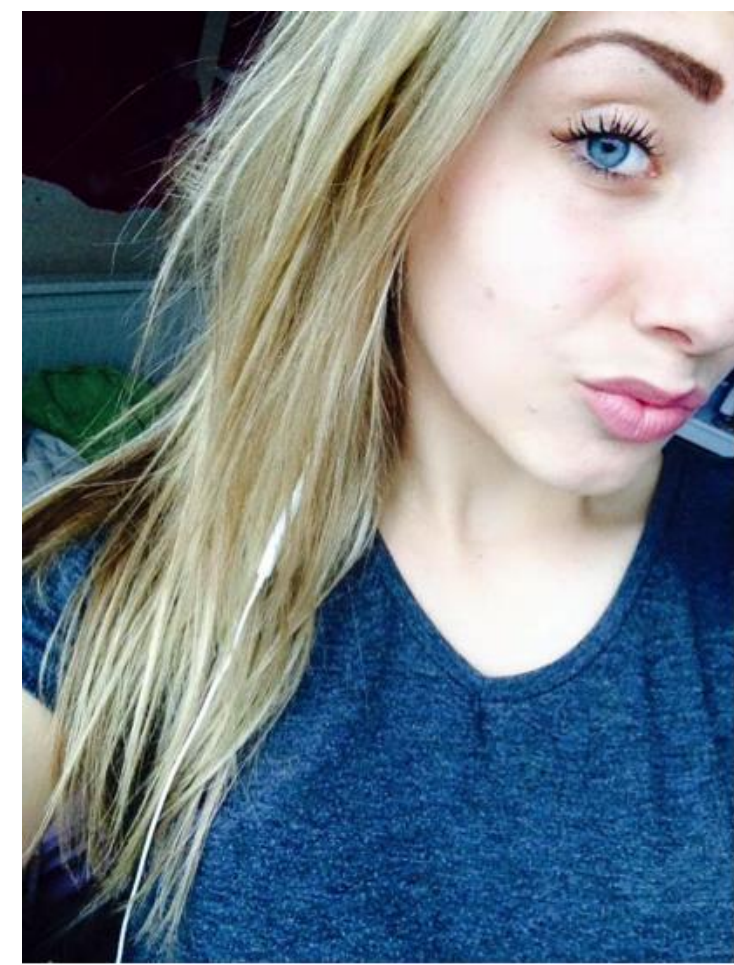

Figure 1. A selfie taken by the author's teenage daughter. Reproduced with permission.
Subject to the norms of social domination and discipline, the virtual, constructed body is objectified even before its visual cyber incarnation, suggesting a degree of docility. The selfie pose trends change as quickly as they spread; the mirror pose, the surprised eyebrow lift, the infamous duck face, the shot from above, the 'I just got up like this' (honest!) and the half face, through to one of the latest trends, the cavity shot, where apparently holding your face as if you have toothache makes you look thinner and vulnerable thus more attractive. This growing taxonomy of poses develops in line with mediatised, capitalist constructions of popular feminine beauty ideologies. In the seminal feminist text The Second Sex, Simone de Beauvoir suggests that the 'ideal of feminine beauty is variable, [but] certain elements remain constant; for one thing since woman is destined to be posessed her body must present the inert and passive quality of an object' (de Beauvoir 1997, 189). These poses attest to the persistence of a traditional, westernised, hegemonic beauty rhetoric.

Some would argue that these poses 'play back [...] well known aspects of feminist media studies, film theory and semiotics' (McRobbie, 17) in a provocative nod towards feminist values of the past. Utilising a deliberate invocation of traditional feminist critique in order to demonstrate that it is no longer necessary; do these images demonstrate self-awareness, choice and enjoyment? Conversely, by their nature, these poses are contrived objectifications and by striking them we allow our bodies to be marked by Wolf's pervasive 'beauty myth'; both affect and effect of a normalizing ideology of appearance. The typical selfie pose, the trademark coquettish tilt of the head that accentuates the jaw line and implies facial slenderness, the raised eyebrows that enlarge the eyes and the pout that draws the eye to the mouth, is an example of 'the mechanisms by which the subject at times becomes enmeshed in collusion with forces that sustain her own oppression' (Bordo 1995, 167). 
In contrast, canonical feminist disdain for selfie practices inflicts a greater degree of docility than the beauty ideologies they embody. Surrendering our self-made images to social media sites is a deliberative and performative activity, albeit structured by the omnipresence of networked devices in most social situations. The successful circulation or 'distribution process' of self-shot images is what leads to their authentication and definition as selfies, signaling 'the availability of the self to the network' (Horning 2014). Selfie-making may not erode the substratum of self-perpetuated panopticism inherent in exploitative social media configurations of identity however the selfie heralds a voluntary entry into established codes of networked identification. Whilst 'neither pleasure nor 'agency' can in themselves be the grounds of a transformative feminist politics' (Ferreday 2014, 143) condemnation and ridicule are equally destructive forms of discipline used by society to control 'stereotypical selfie takers: young women' (Rettburg 2014).

For many women selfies are demonstrative of a 'new regime of sexual meanings based on female consent, equality, participation and pleasure' (McRobbie 2009, 18). This is evidenced in the writing of online bloggers such as Michelle Cason writing for online magazine feminspire who asserts that 'sexuality and feminism are not mutually exclusive, and [she's] tired of hearing the "bad feminist" debate' (Cason 2014). Persistent attempts to critique the latent narcissism inherent in selfies is as problematic and disciplinary as ideological constructs of feminine beauty. As women move away from masculinist values of modesty and chastity and use networked platforms to share images that embrace all forms of femininity, girlishness and exhibitionism included without censorship, the reaction of society has been derision and mockery. The generalization and pathologising of images that celebrate femininity seems, ironically, to insist on docility.

\section{\#nomakeupselfies: a breast cancer survivor's perspective}

The \#nomakeupselfie phenomenon paradoxically epitomized both a docile affectation of dominant beauty norms and a post-feminist celebration of femininity. As a breast cancer survivor my contemplation of the meme was complex; I was disconcerted by the images for several reasons but I also felt guilty for being skeptical. The trend ultimately raised enough money to fund ten new research projects undoubtedly contributing to breakthroughs in the treatment of cancer, therefore I found it difficult to justify being critical. Clinging tentatively to my newfound breast cancer 'survivor' status but constantly plagued by the reality of recurrence I wondered if I shouldn't just be grateful for these types of charitable campaign. My Facebook news feed filled with images of naturally beautiful faces that were accompanied by comments such as '\#horrifficsonotphotogenic' or 'Here goes ..... The ugly shot'. As self deprecation and humiliated apologies abounded I recognised that criticism of the social conventions that lead to trends such as these is not a personal or vindictive slight on those who have chosen to take part. Identifying and critiquing the multiple power structures, ideologies and rationalities that the \#nomakeupselfie perpetuated does not detract from any charitable success.

My reservations, whilst resonating with the wider criticism that the phenomenon incurred, were specifically influenced by my nuanced position as a young, female, selfie-taking, feminist, academic, breast cancer survivor. This phenomenological reading of the meme, that straddled all of these categories of my own lived experience, is centered on three distinct yet conversant issues: the problematic relationship between breast cancer and beauty; the trivialization, infantilisation and sexualisation (Sulik 2014) of the disease inherent in contemporary breast cancer culture and the self-commodification of the female body as part of a consumer activist transaction.

My subjective observations and concerns were situated at the interstice between the homogenizing ideological practices of socially expected beauty regimes and the complexification of these for 
women with breast cancer. Women with a breast cancer diagnosis 'live with the fear that they will like their face less than they did yesterday' (Park 2014). The sustained, unavoidable and permanent loss of corporeal visual signifiers of femininity demands a re-evaluation of self-identity that is incommensurable with the removal of externally applied products that serve to highlight or accentuate incarnate femininity. The removal of make-up is incomparable to the life saving but ultimately body changing surgery and the simultaneous loss of hair, eyebrows, eyelashes and finger nails that accompanies breast cancer treatment; changes that no amount of cosmetics can conceal.

Whilst, it is undoubtedly safe to suggest that most participants were not naive enough to assume that their actions were akin to the reality of cancer, there was an omnipresent tone of unity sustained through the concept of bravery and ensuing camaraderie that accompanied the images. This was a trend that despite attracting the participation of celebrities was pursued by 'ordinary people'. In her book Self-representation and Digital Culture, Nancy Thumim explores the category 'ordinary people' in relation to self-representation, one of her suggestions is that the term 'is used to unite given groups of people under a unifying heading' $(2012,23)$. Participants in the \#nomakeupselfie united as a gendered community to 'raise awareness' of a disease that threatens femininity. This resulted in two significant consequences. Firstly it counters the utopian vision of a postgender society envisioned by cyber-feminists of the 1980s and 1990s; the women taking part in this meme were united by a retro-essentialist corporeal classification of womanhood. Secondly, by its very nature something that raises awareness is something extra-ordinary so this public, albeit virtual, appearance without the shield of makeup was categorized as both bold and peculiar. Here we must decide if women with (or post) a breast cancer diagnosis are to be included in this category of 'ordinary people' or not. If they are then by default this activity suggested that the appearance of a female body marked by the visible signs of cancer shares the peculiarity ascribed to cosmetic free faces. But not including those marked by breast cancer in this category speaks heavily to exclusion based on the corruption and disease of female signification. Being confronted by images of healthy women who felt the need to condemn their own looks was a proverbial slap in the face as I struggled to re-negotiate my own femininity. The selfies I posted in the reconfiguration of my post cancer online self were not accompanied by profuse apologies for not being typical of feminine beauty. Here I echo the sentiments of the late Eve Kosofsky Sedgwick: 'I would warmly encourage anyone interested in the social construction of gender to find some way of spending half a year or so as a totally bald woman' (Sedgwick in Price and Shildrick 1999, 153).

The internet has long been a realm where 'women with breast cancer not only receive information about the illness but also compose and circulate their own stories' (Pitts 2004, 33). Throughout my diagnosis, during my active treatment and now, as a so called 'survivor' my membership to networked cyber space has been, and is, a critical forum. Upon diagnosis I instinctively turned to the internet to learn more about the specifics of the disease, surgery, treatment and prognosis. During chemotherapy I was able to socialize with friends at times when my compromised immune system made sharing a physical space with others dangerous. I became a member of YBCN (Younger Breast Cancer Network) on Facebook. My days consisted of virtually communicating at length with other women in the same situation. In this virtual space we got angry and raved, laughed and cried and when members of the group died we mourned, together. I used the internet (and the practice of taking selfies) in what I believed was empowered self-documentation and negotiation of my illness. The net was an intrinsic part of my recovery but as Pitts suggests 'cyberspace, which has been hailed by some as a libertarian utopia of free speech, free virtual bodies and free selves, must be seen instead as a site where definitions of situation, body and identity are both contested and are influenced by power relations' $(2004,53)$.

Although never stated by the participants themselves, it was widely assumed that 'the idea of a "no make-up selfie' as something unusual and daring might suggest that it is otherwise unusual for a 
woman to appear bare-faced in public' (Ferreday 2014, 142). This implication resulted in widespread feminist critique of the meme. The feminist blogger Yomi Adegoke, interviewed on $\mathrm{BBC}$ radio 4's Today programme, suggested that rather than normalising women going without makeup the trend was having the opposite effect. She drew comparisons with sitting in a bath tub of baked beans or shaving your head for cancer research highlighting that classifying the exposure of makeup free faces as extraordinary was problematic (Today 2014). Some women with breast cancer chose to participate in the \#nomakeupselfie, taking pictures that explicitly displayed the visual signifiers of their cancerous bodies, infinitely braver and more meaningful than a revelation of a cosmetic free face. Framed as part of this meme, these images of cancerous bodies resonated with hegemonic ideals of feminine beauty. The fleeting nature of the \#nomakeupselfie, according to critics, implied that women should usually wear make-up; this sentiment could also be tacitly applied to the breast cancer patients who participated. It infers that sharing images of themselves without the menagerie of items used in the concealment of their disease should be an extraordinary unique event, a momentary phenomenon to be swiftly replaced by a more socially palatable erasure and concealment of the signs of disease. The meme presented the disease in a way that has become familiar in breast cancer culture, enforcing heteronormative ideals, pressurizing women to rebeautify themselves, masking signs of illness to present the obligatory image of the smiling optimistic 'survivor'.

Popularized representations of breast cancer and the 'pinkification' of the disease places traditional assumptions of feminine beauty at the center of the awareness discourse; it foregrounds prettiness, youth, sexuality and femininity. The colour pink is now synonymous with breast cancer awareness, survivorship and fund raising, but 'pink, the quintessential colour of femininity, represents everything breast cancer is not' (Sulik 2014). Having breast cancer paradoxically challenges received notions of femininity whilst simultaneously plunging those with a diagnosis into a suffocating world of femaleness. The \#nomakeupselfie explicitly exposed this socially constructed feminizing relationship and is part of the reproduction of pink consumer culture that de-sensitizes and falsely implies that breast cancer is non-threatening.

Since Evelyn Lauder launched the pink ribbon campaign in the early 1990s breast cancer awareness and survivorship has morphed into the pervasive pink culture that symbolizes the disease today. As Liz Powell suggests 'the pink ribbon is not a simple visual signifier for breast cancer it is loaded with ideological meaning' $(2013,44)$; this ideological meaning is inseparable from its inception by the beauty industry. Pink culture is fuelled in two distinct ways, firstly by capitalist marketing, branding and corporate investment (Sulik 2014). Evident in the prolific use of the pink ribbon symbol by companies to endorse their products and the excess of commercial merchandise such as pink ribbons, balloons, badges etc. Thinking pink is also propagated by social interaction and the popularization of activism as a fashionable pass time, typified by the Race for Life. Breast cancer awareness is trivialized by an ethos of fun and participation characterized by online games such as those that require women to post the colour of their underwear, or yet more absurdly, where they keep their handbag, as a Facebook status. The \#nomakeupselfie phenomenon is part of the trope of hashtag activism that diverts attention from considered awareness to render breast cancer palatable and engaging.

The feminization of breast cancer awareness is framed by codified gender binaries, apparent in the exclusion of men from \#nomakeupselfies. By reinforcing and foregrounding normative ideologies of femininity including vulnerability, fragility and emotionality, the pink ribbon culture aggrandizes masculine archetypal qualities such as strength, courage and independence. Categorizing breast cancer as an exclusively female concern leads to an escalation of the stigma and lack of awareness surrounding men with the disease. Furthermore, this representational marginalization of men exacerbated the hyper-sexualisation of the disease; the prioritization of the sexual desirability of 
breasts over health and well-being. Some men chose to join the phenomenon by taking selfies wearing make-up in a parody of the female version. The aim was to support the campaign via these self-emasculating images, but a humour-fuelled deviation from the accepted norms of masculinity served to intensify the notion of humiliation accompanying the images of the unadorned women's faces. These men chose to apply make-up in a bid to subvert social constructions of normative gendered behavior and in doing so they ultimately re-enforced the use of cosmetics as a homogenizing feminine practice. This ultimately reconstituted the meta-powers of distinctive binaries of gender ideology.

These selfies demonstrated the persistence of objectification through poses that, ironically despite the revelation of the subject's unadorned face, distinctly lacked 'authenticity'. Whilst it is true that all contrived poses by their very nature lack 'truth' these images seemed at once to expose and conceal the reality of being a woman. In the absence of make up many participants employed what are termed by Foucault as 'coercions that act upon the body, a calculated manipulation' $(1977,138)$ of hair, angles, lighting, poses and clothing.

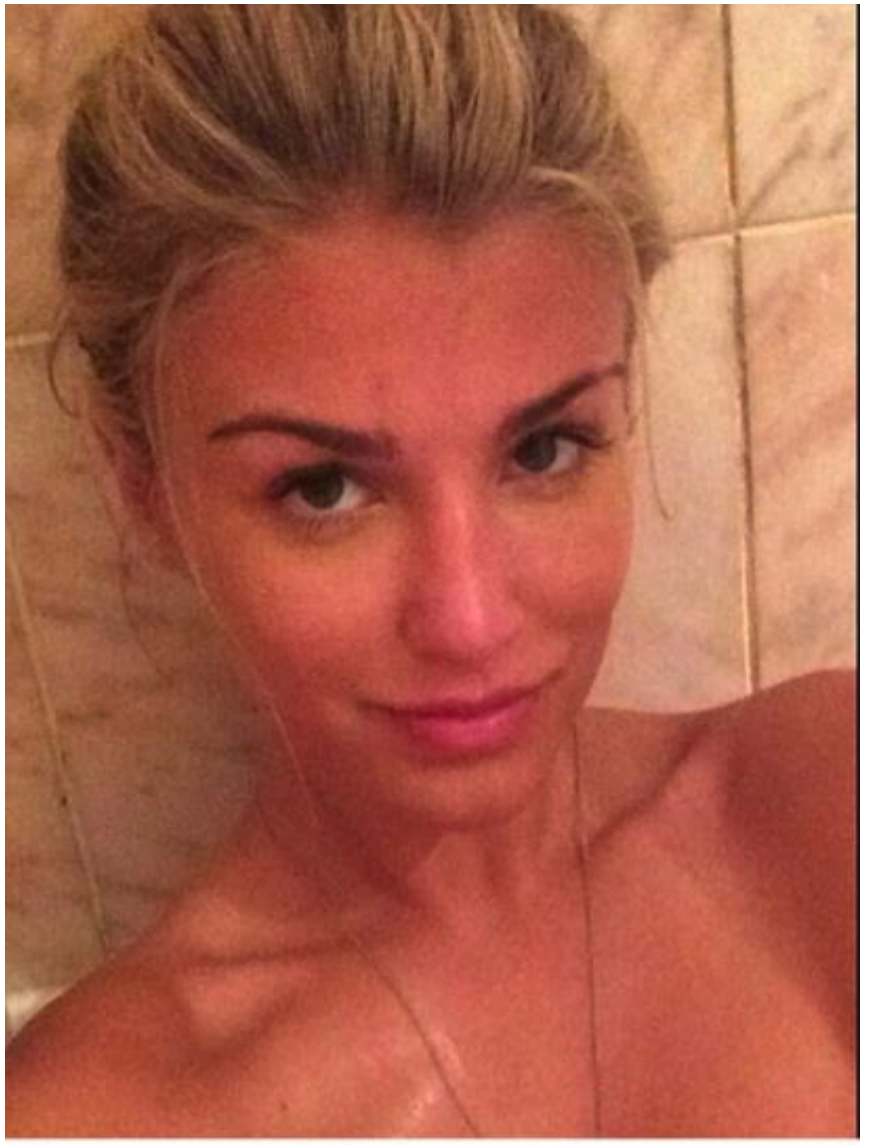

Amy Willerton amyeillerten Mar 19 moMakeUpSelfieforCancer ACancerAwareness from the bath tub) pic twitter comirSOPCIIZEAC

\& Reply ea Retweet $\star$ Favorite

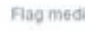

These images also 'transmit elements of the rhetorical scene to others' (Losh 2014) through a careful consideration of foreground and background and items displayed in the peripheral space around the subjects face. Many participants chose to take pictures in bed or in the bath monopolizing the opportunity to garner 'social and sexual recognition' (McRobbie 2007, 255) through the strategic employment of semiotic signifiers of the sexual desirability of the rest of their bodies. Likes and complimentary comments were in abundance, declarations of 'beautiful' and 'well done - hun' created a pervasive sense of narcissism, a seeking of affirmation ensconced under the socially acceptable banner of raising awareness. Rettburg asks 'why are we so afraid of being thought exhibitionists?' (2014, 17). Whilst the celebration of appearance and femininity inherent in selfies should be championed as a selfaware over throwing of masculinist values, seeking to camouflage these as activism speaks less to agency and more to an internalization of Wolf's 'beauty myth'.

Figure 2: Amy Willerton's \#nomakeupselfie 
The practice of nomination is accompanied by an ensuing sense of obligation. Participation in this selfie meme was a definite choice made by all participants but any non-conformity seemed to demand an explanation or apology for not supporting the cause or responding to the rallying calls of (network) friends. The \#nomakeupselfie is part of the neo-liberal individualist trope of consumer activism; as Sulik suggests, 'pink consumption has become a trendy pass time' $(2014,655)$. This is part of the trend in society to purchase merchandise and charity branded products and use, wear or promote them publicly in an outward demonstration of our altruism and support of a chosen cause. Being part of this meme and the wider breast cancer culture is hailed as empowering, pro-women and supportive but in reality is part of a much wider tendency to align ourselves with fashionable causes as a means of generating cultural capital. Horning describes the practice of selfie taking as a 'neoliberal command to develop a self as a kind of capital stock and serially reproduce oneself in self-advertisements' (2014). This invokes Alison Hearn's sentiment that 'ultimately your personal brand is not only a pretty veneer; it is intended to be a rhetorically persuasive version of yourself' (2008, 206). During the \#nomakeupselfie, rather than purchasing charitable merchandise in a financial transaction women turned their bodies into objectified commodities to be traded for cultural capital and inclusion in a fashionable social movement. Re-branding themselves through posed images and comments of self-deprecation, \#nomakeupselfie images depicted participants as simultaneously demure subordinates to beauty trends and brave anti-cancer activists.

\section{Conclusion}

The consideration of the selfie through a post-feminist lens and the interrogation of the contradictory and divided position of femininity that is ensconced in self-representation is a timely and important endeavour. Since the mid-1980s cyber-feminists have been optimistic about net utopianism; the de-construction of traditional gender roles and the mobilization of empowered, selfdetermined constructions of identity in an inherently liberating forum. Selfies, as a networked cultural phenomenon, are ripe with the potential to subvert hegemonic normative ideologies. They present us with the opportunity for agency, authorship and control. The emergence of new technologies such as smartphones has increased our access to the internet granting us the opportunity to self-story via instantaneously uploaded images taken of ourselves, by ourselves. 'Ordinary people' regardless of gender must be free to celebrate their appearance and use selfcaptured images in the construction of their online identities without fear of derision or ridicule. However, what this examination has shown is that feminist discourse surrounding selfies is ubiquitous, pluralistic and complex. Despite pro-selfie claims of agency, the internalization and replication of dominant social norms is evident in the majority of online selfie images. This problematises, if not contradicts, the notion of empowerment despite post-feminist claims of freedom and choice.

The no make-up selfie trend is a particularly problematic medium through which to consider the practice of selfies. The meme called for 'women' to unite under a homogenizing physiological category; use (or rather for one fleeting moment chose not to use) ideological practices of beauty to raise awareness; this was done in the name of a disease that threatens and corrupts femininity from within the female body whilst simultaneously thrusting a victims femaleness to the forefront of their identity. Whilst Ferreday suggests that \#nomakeupselfies 'represent a far more sophisticated and self-aware rejection of masculinist values than femininity's detractors would allow' $(2014,143)$, I question this 'self-awareness' and implied emancipation. The meme highlights the relationship between dominant power structures, coercive practices and self-regulation through a complexification of charitable advocacy, self commodification and homogenising ideology. 


\section{References}

Adegoke, Y. (2014) The 'no makeup selfie' online campaign. BBC Today [online] 21 March 2014. Available at http://www.bbc.co.uk/programmes/p01vzxnl Accessed 26 April 2015

Adewumni, B. (2013) The rise and rise of the selfie. The Guardian [online], 2 Apr. Available at http://www.theguardian.com/artanddesign/2013/apr/02/rise-and-rise-of-the-selfie. Accessed 13 Aug 2014.

Bordo, S.(1995) Unbearable weight, feminism, western culture and the body. Los Angeles: University of California Press.

Daniels, J. (2009) Rethinking cyber-feminisms: Race, gender and embodiment, Women's Studies Quarterly, 37(1), pp. $101-124$.

De Beauvoir, S. (1997) The second sex. London: Vintage

Dean, M. (2010) Governmentality: power and rule in modern society. London: Sage Publications Ltd

Feminspire (2014) 'Why my sexy selfies are a feminist statement', [online], 22 May. Available at http://feminspire.com/why-my-sexy-selfies-are-a-feminist-statement. Accessed 05 May 2015.

Ferreday, D. (2014) 'The feminine art of failure: queering feminist spectatorship', Quaderns de Psicologia, 16 (1), pp. 141-142.

Foucault, M. (1988) Technologies of the self, in L. Martin, H. Gutman and P. Hutton (eds), Technologies of the self: A seminar with Michel Foucault, Amherst: University of Massachusetts Press, pp. 16-49.

Foucault, M. (1977) Discipline and Punish. The Birth of the Prison. London: Penguin.

Haraway, D. (2000) 'A manifesto for cyborgs: Science, technology and socialist feminism in the 1980s', in G. Kirkup, L. Janes, K. Woodward and F Hovenden (eds) The Gendered Cyborg: A Reader, Oxon: Routledge, Kindle Version. Accessed 28 March 2015 from Amazon.com

Hearn, A. (2008) 'Meat, mask, burden. Probing the contours of the branded 'self', Journal of Consumer Culture, 8(2), pp. 197 - 217.

Horning, R. (2014) 'Selfies without the self', [online], 23 Nov. Available at http://thenewinquiry.com/blogs/marginal-utility/selfies-without-the-self/. Accessed 24 Nov 2014.

Lemke, T. (2002) Foucault, governmentality and critique. Rethinking Marxism: A journal of economics, culture and society, 14(3), pp. 49-64.

Losh, E. (2014) Beyond biometrics: feminist media theory looks at selfiecity

Available at http://d25rsf93iwlmgu.cloudfront.net/downloads/Liz_Losh_BeyondBiometrics.pdf. Accessed 27 Aug 2014

Lorde, A. (1999) 'A burst of light: living with cancer', in J. Price and M. Shildrick (eds) Feminist 
Theory and The Body, United Kingdom: Edinburgh University Press, pp. 149 - 153.

Markham, A. (2013) 'The dramaturgy of digital experience', in C. Edgley (ed), The Drama of Social Life, Surrey: Ashgate Publishing Ltd, pp. 279 - 293.

McRobbie, A. (2009) The aftermath of feminism. Gender, culture and social change. London: Sage Publications Ltd.

McRobbie, A. (2007) Post - feminism and popular culture. Feminist media studies, 4(3), pp. 255264.

Mizrach, S. (2009)

'Lost in Cyberspace: A cultural geography of cyberspace', [online] Available at: http://www2.fiu.edu/ mizrachs/lost-in-cyberspace.html Accessed 26 Aug 2014.

Oxford Dictionaries; Language matters (2015) Available at:

http://blog.oxforddictionaries.com/press-releases/oxford-dictionaries-word-of-the-year2013/ Accessed 29 Mar 2015.

Park, G. (2014) 'No makeup selfies a slap in the face to women with cancer', [online] Available at http://www.neontommy.com/news/2014/03/nomakeupselfie-trend-slap-face-women-cancer Accessed 26 Aug 2014.

Pitts, V. (2004). Illness and Internet empowerment: writing and reading breast cancer in cyberspace, Health: An Interdisciplinary Journal for the Social Study of Health, Illness and Medicine, 8(1), pp. 33-59.

Powell, L. ( 2013) Refashioning the post mastectomy body in How to Look Good Naked, Film, Fashion and Consumption 2(1), pp $43-54$.

Rettburg, J. W. (2014) Seeing ourselves through technology: How we use selfies, blogs and wearable devices to see and shape ourselves, Basingstoke: Palgrave Macmillan, Kindle Version, Accessed 18 Feb 2015 from Amazon.com

Schwarz, O. (2011) Subjectual visibility and the negotiated panopticon: on the visibility-economy of online digital photography. [online] Available at http://scholar.harvard.edu/files/schwarz/files/schwarz_2011_subjectual_visibility_and_the_n egotiated_panopticon.pdf Accessed 4 May 2015

Sedgwick, E.P. (1999) 'Breast cancer: An adventure in applied deconstruction', in J. Price and M. Shildrick (eds) Feminist Theory and The Body, United Kingdom: Edinburgh University Press, pp. $153-157$.

Sulik, G. (2014) \#RETHINKPINK Moving beyond breast cancer awareness, Gender and Society, 28(5), pp. 655-678.

Thumim, N. (2012) Self-representation and digital culture, Basingstoke: Palgrave Macmillan.

Tiidenberg, K. (2014) Bringing sexy back: reclaiming the body aesthetic via self - shooting. Cyberpsychology: Journal of Psychosocial Research on Cyberspace, 8(1), Article 3. 
Waskul,D., Douglass, M. And Edgley, C. (2000) Cybersex: Outercourse and the enselfment of the body, Symbolic Interaction, 23(4), pp.375-398

Westlake, E. J. (2008) Friend me if you Facebook: Generation Y and performative surveillance. The Drama Review. 52(4), pp. 21-40

Willerton, A. \#NoMakeUpSelfieForCancer. [online] Available at http://www.dailymail.co.uk/femail/article-2586123/Going-bare-faced-NOT-courageous-Asno-makeup-selfies-raise-2m-charity-young-feminist-slams-trend-model-Amy-Willertonargues-good-message.html Accessed 8 May 2015

Willerton, A. Twitter. [online] Available at https://twitter.com/amywillerton/media Accessed 27 May 2015

Wolf, N. (1991) The beauty myth, London: Vintage.

Claire Hampton's research interests lie at the intersection between performance, contemporary culture, embodiment, trauma theory and gender studies. She is currently completing her PhD at Brunel University London where her research addresses the performance of female trauma through visual self- documentation, focusing on the popular cultural phenomenon of selfies. She also works as a full-time lecturer in Drama at the University of Wolverhampton.

Email: c.hampton@wlv.ac.uk 